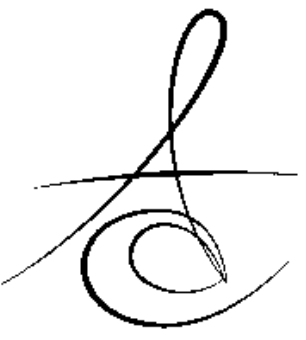

\section{ÇENELERİN BENİNG FİBROOSSEÖZ LEZYONLARININ KONİK IŞINLI BİLGİSAYARLI TOMOGRAFİ ile DEĞERLENDİRİLMESİ}

\section{EVALUATION BENIGN FIBROOSSEOUS LESIONS OF THE JAW WITH CONE BEAM COMPUTED TOMOGRAPHY}

\author{
Uzm. Dt. Katibe Tuğçe TEMUR*
}

Makale Kodu/Article code: 3258

Makale Gönderilme tarihi; 02.01.2017

Kabul Tarihi: $\quad 21.02 .2017$

\section{öz}

Benign fibroosseöz lezyonlar (BFOL), kemik veya sement gibi kalsifiye yapıları içeren fibröz doku ile karakterize benzer mikroskobik özellikleri olan kemik içi lezyon grubudur. BFOL klasik olarak, fibröz displazi, osseöz displaziler (semento-osseöz displazi), fibroosseöz tümörler (ossifying fibrom) olarak sınıflandırılır. Bu lezyonların bazıları histolojik olarak teşhis edilirken, çoğu klinik, mikroskopik ve radyografik özelliklerin kombine değerlendirilmesini gerektirir. Bu makalede üç farklı tip benign fibroosseöz lezyonunun klinik, radyolojik ve konik ışınlı bilgisayarlı tomografi (KIBT) bulguları sunulmuştur.

Anahtar Kelimeler: Konik Işınlı Bilgisayarlı Tomografi, Bening Fibroosseoz, Osseöz displazi, Fibröz Displazi

\section{ABSTRACT}

Benign fibroosseous lesions (BFOL) are a group of intraosseous lesions with microscopic features similar to characterized by fibrous tissue containing calcifications such as bone or cement. Benign fibroosseous lesions are classically categorized as fibrous dysplasia, osseous dysplasia (cemento-osseous dysplasia), fibroosseous tumors (ossifying fibroma). Whereas some are diagnosable histologically, most require a combined assessment of clinical, microscopic and radiologic features. In this article, clinical, radiological and cone beam computerized tomography (CBCT) findings three different types of bening fibroosseous lesions are presented.

Key Word: Cone-Beam Computerized Tomography, Bening Fibro-Osseous, Osseous dysplasia, Fibrous dysplasia

tipinden biri olan monostotik tip \%80-85 oranında görülür ve en sık kraniyofasiyal kemikler, kosta, femur ve tibia bölgelerinde ortaya çıkar. Poliostotik tip, monostotik tipten farklı olarak birden fazla kemiği tutabilir, sıklıkla 10 yaş altı çocuklarda görülür. Poliostotik tip ile çoklu endokrin bozuklukları ve cilt pigmentasyonu (cafe-au-lait lekeleri) birlikte görülürse, bu klinik tabloya McCune-Albright sendromu denir ${ }^{3}$. Fibröz displazi' de radyolojik görünüm lezyonun evresine bağlıdır. Erken evrede lezyon radyolüsent görünür ancak ilerleyen evrelerde opasite artışı ile birlikte mikst görüntü (buzlu cam) verir ${ }^{4}$.

\footnotetext{
${ }^{*}$ Serbest Hekim

${ }^{* *}$ Çukurova Üniversitesi, Diş Hekimliği Fakültesi, Ağız Diş ve Çene Cerrahisi AD, Adana.
} 
Osseöz displaziler (semento-osseöz displazi) en yaygın görülen bening fibroosseöz lezyon türüdür. Klinik ve radyografik özelliklerine göre, periapikal osseöz displazi (periapikal semento-osseöz displazi), fokal osseöz displazi (fokal semento-osseöz displazi), florid osseöz displazi (florid semento-osseöz displazi) olarak 3'e ayrılırlar ${ }^{3}$. Periapikal osseöz displazi sıklıkla orta yaşı siyahi kadınlarda görülen ve tipik olarak mandibular anterior dişlerin kökü ile ilişkili bir lezyondur. Radyografide periapikal osseöz displazi lezyonları erken evrede radyolusent, ileri evrelerde lezyon önce mikst sonra ince radyolusent bant ile çevrili $1 \mathrm{~cm}^{\prime}$ den küçük radyoopak kitle şeklinde görülür. Periapikal osseöz displazinin yaygın formu olarak bilinen florid osseöz displazi, sıklıkla orta yaşlı siyahi kadınlarda, bilateral, simetrik, her iki çenenin posterior bölgelerinde nadir rastlanan bir lezyondur. Radyografide florid osseöz displazi lezyonları erken evrede radyolusent, ileri evrelerde radyolusent bant ile çevrili radyoopak kitleler şeklinde görülür. Genellikle asemptomatiktir ve rutin radyografik incelemede tesadüfen fark edilir. ${ }^{4-6}$ Özellikle asemptomatik olgularda konvansiyonel radyografiler lezyona tanı koymak için yararlıdırlar. Ancak bilgisayarlı tomografi (BT) gibi vücudun herhangi bir bölgesinin kesit görüntüsünü oluşturabilen cihazlar ile bu lezyonların değerlendirilmesi kolaylaşır $\quad 7,8$. Bilgisayarlı tomografilerden daha iyi uzaysal çözünürlüğe sahip, metal artefaktlarının daha az olduğu, efektif radyasyon dozunun çok daha düşük olduğu konik ışınlı bilgisayarlı tomografiler bu lezyonların incelenmesinde BT ye göre avantajlıdır ${ }^{9,10}$.

Bu çalışmada üç farklı tip benign fibroosseöz lezyonunun klinik, radyolojik ve konik ışınlı bilgisayarlı tomografi (KIBT) bulguları sunulmuştur.

\section{OLGU-1}

27 yaşındaki erkek hasta fasiyal asimetri ve parestezi şikayeti ile kliniğimize başvurdu. Hastanın anamnezinde herhangi bir sistemik hastalığı olmadığı öğrenildi. Alınan panoramik radyografide, alt çene sağ kanin dişi ile sağ ikinci molar diş arasında kemik trabekülasyonunda, buzlu cam görüntüsü ile uyumlu bir farklılık görüldü. Lezyonun çevre dokular ile ilişkisini 3 boyutlu değerlendirmek için KIBT görüntüleri elde edildi. Aksiyel, koronal kesitlerde mandibula sağ kanin dişi ile 2.molar diş arasında bukko-lingual yönde kortekste ekspansiyon, incelme, kemik trabeküllerinin küçük ve çok sayıda (buzlu cam görüntüsü) olduğu ve mandibular kanalın süperior yönde yer değiştirdiği görüldü. Diğer kafa kemiklerinde lezyon saptanmadı (Resim-1, Resim-2). Lokal anestezi altında biyopsi alındı. Histopatolojik incelemede lezyonun, fibroosseöz lezyon ile uyumlu olduğu rapor edildi. Klinik, radyografik ve histopatolojik inceleme sonucunda fibröz displazi tanısı konuldu. Vakaya cerrahi müdehale planlandı.
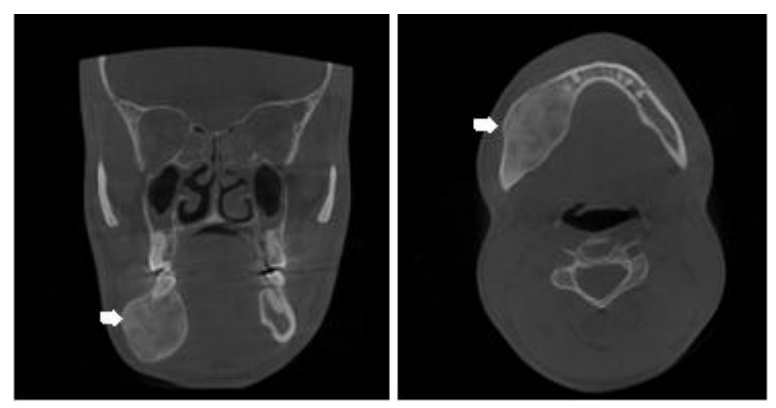

Resim1. Olgu-1' e ait KIBT koronal kesitte (solda) ve aksiyal kesitte (sağda) bukkal ve lingual korteksin ekspansiyon görüntüsü.

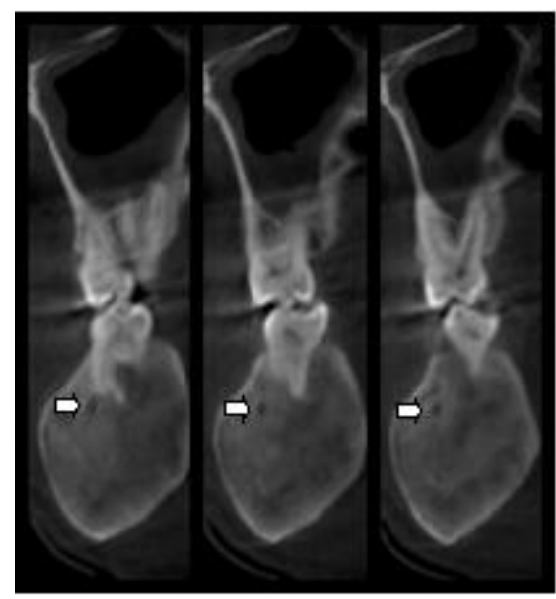

Resim 2. Olgu-1' e ait süperior yönde yer değiştiren mandibular kanalın KIBT kesit görüntüsü.

\section{OLGU-2}

48 yaşındaki kadın hasta diş eksikliği şikayeti ile kliniğimize başvurdu. Dental implant talebi olan hastanın anamnezinde herhangi bir sistemik hastalığı olmadığı öğrenildi. Alınan panoramik radyografide alt çenede yaygın, bilateral radyolusent bant ile çevrili radyoopak lezyonlar gözlendi. İlgili dişlerde herhangi bir semptom yoktu. Asemptomatik olan dişlere yapılan

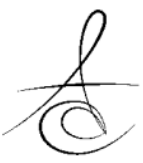


vitalite kontrollerinde dişlerin vital olduğu belirlendi. Lezyonun çevre dokular ile ilişkisini 3 boyutlu değerlendirmek için KIBT görüntüleri elde edildi (Resim-3, Resim-4). Kesit incelemelerinde alt çene sağ kanin, sağ ikinci premolar ve sağ molar dişler, alt çene anterior dişler ve alt çene sol kanin, birinci premolar, sol molar diş kökleri ile ilişkili multiple, düzenli sınırlı hipodensif alanlar içerisinde hiperdensif odaklı lezyonlar izlendi. KIBT kesitlerinde kortekste ekspansiyon, perforasyon görülmedi. Lezyonlarin mandibular kanal ile ilişkili olmadığı ve mandibular kanalın süperiorunda lokalize olduğu görüldü. Lokal anestezi altında biyopsi alındı. Histopatolojik incelemede lezyonun, fibroosseöz lezyon ile uyumlu olduğu rapor edildi. Klinik, radyografik ve histopatolojik inceleme sonunda florid osseöz displazi tanısı konuldu. Lezyonun asemptomatik olması sebebiyle herhangi bir tedavi düşünülmedi. Diş eksikliği için dental implant talep eden hastamıza, diş destekli kuron köprü protezi önerildi. Hastaya lezyonun malign özellikte olmadığı anlatıldı ve 6 aylık rutin takipler önerildi.

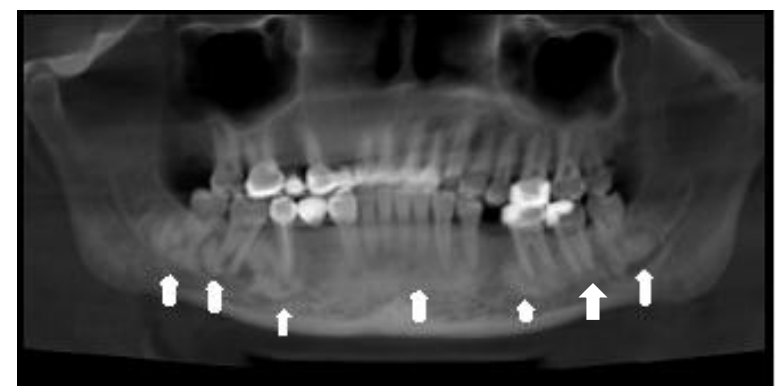

Resim 3. Olgu-2' ye ait mandibulada yaygın, bilateral hipodensif alanlar içerisinde hiperdensif görüntü veren lezyonların KIBT panoramik kesit görüntüsü

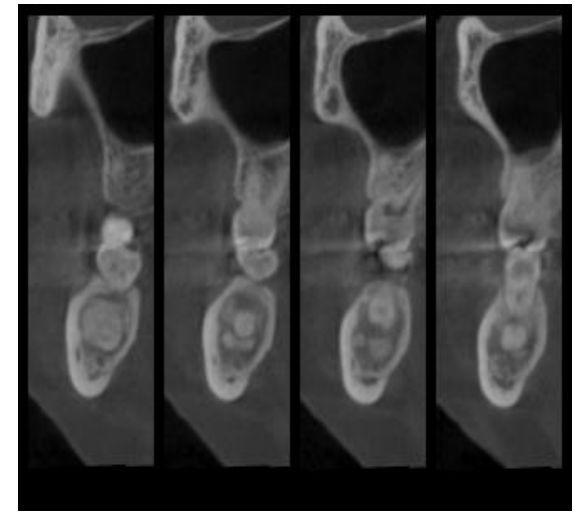

Resim 4. Olgu-2' ye ait mandibular sağ ikinci molar diş bölgesinde hiperdensif lezyonların KIBT kesit görüntüleri

\section{OLGU-3}

30 yaşındaki kadın hasta mandibular sağ ikinci molar diş kaynaklı spontan ağrı şikâyeti kliniğimize başvurdu. Hastanın anamnezinde herhangi bir sistemik hastalığı olmadığı öğrenildi. Hastanın intraoral muayenesinde mandibular sağ ikinci molar dişinde derin dentin çürüğü görüldü. Muayene sonrasında alınan panaromik radyografta mandibular sağ ikinci molar dişin apikalinde radyolusensinin yanı sıra, mandibulada kanin, premolar ve molar diş kökleri ile ilişkili radyolusent alanlar görüldü. İlgili dişlerde, mandibular sağ ikinci molar diş haricinde herhangi bir semptom yoktu. Asemptomatik dişlere yapılan vitalite kontrollerinde, dişlerin vital olduğu belirlendi. Lezyonun çevre dokular ile ilişkisini 3 boyutlu değerlendirmek için KIBT görüntüleri elde edildi (Resim-5, Resim-6). KIBT kesitlerinde kortekste ekspansiyon, perforasyon görülmedi. Semptom olmayan dişler ile ilişkili lezyonlar için herhangi bir endodontik tedavi uygulanmadı. Klinik, radyografik ve KIBT incelemeleri sonunda lezyonun erken evredeki periapikal osseöz displazi ile uyumlu olduğuna karar verildi, biyopsiye gerek görülmedi. Hastaya lezyonun malign özellikte olmadığı anlatıldı ve 6 aylık rutin takipler önerildi.

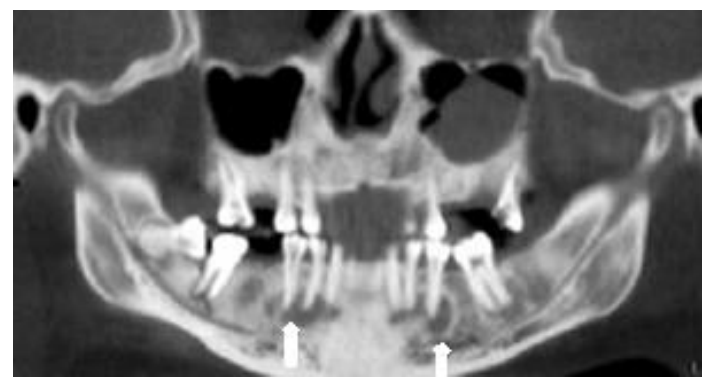

Resim 5. Olgu-3'e ait mandibular anterior diş ve 33, 34, 35, 43, 44, 45,46 nolu diş kökleri ile ilişkili hipodensif lezyon KIBT panoramik kesit görüntüsü 


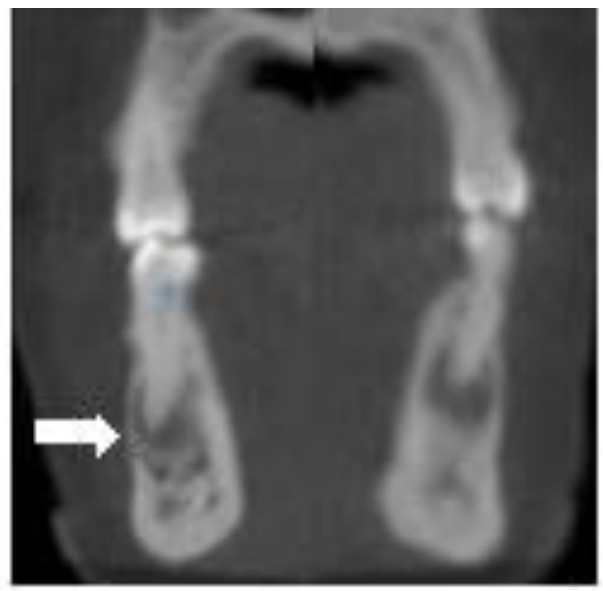

Resim 6. Olgu-3'e ait 45 ve 35 nolu diş kökleri ile ilişkili hipodensif lezyon KIBT kesit görüntüsü

\section{TARTIŞMA}

Fibröz displazi genellikle cinsiyet ayrımı yapmaksızın, çocukluk ya da adolesan döneminde görülen benign fibroosseöz bir lezyondur. Fibröz displazinin en sık (\%80) tek odaklı tipi (monostotik) görülür. Monostotik form tek bir kemiği tutar. En hafif görülen formdur ve baş boyun bölgesinde maksilla ve mandibula en sık tutulan kemiklerdir. Olgumuz 27 yaşında erkek hastada görülen sadece mandibulada kemik tutulumu olan bir monostotik fibröz displazi vakasıydı (Olgu-1). Fibröz displazi vakaları, asemptomatik kalabilir veya kemiklerinin kalınlaşması ile yüzde asimetri meydana gelebilir $^{11}$. Ancak paranazal sinüs, orbita ve kafa tabanında foraminalar bölgesinde kemik tutulumu olan vakalarda baş ağrısı, görme kaybı, proptozis, burun tıkanıklığı, anosmi ve işitme kaybı gibi çeşitli semptomlar görülebilir ${ }^{5}$. Mandibula tutulumu olan vakalarda, mandibular kanal süperior veya inferior yönde yer değiştirebilir. Özellikle mandibular kanalın süperior yönde yer değiştirmesi fibröz displazi için karakteristik olduğu bildirilmiştir ${ }^{6,12}$. Bu özellik fibröz displazinin diğer lezyonlardan ayrılmasını sağlar. Olgumuzda, mandibular kanalın süperior yönde yer değiştirdiği görüldü (Olgu-1). Fibröz displazi' de radyolojik görünüm lezyonun evresine bağlıdır. Erken evrede lezyon radyolüsent görünür ancak ilerleyen evrelerde opasite artışı ile birlikte karakteristik mikst (buzlu cam) görünümdedir. Lezyon çevre kemik doku ile devamlılık gösterir ve radyografide sınırları net değildir ${ }^{6}$. Bazı vakalarda radyografik incelemelerde, paranazal sinüs- lerin ortadan kalktığı görülebilir ${ }^{13}$. Olgumuzda lezyonun karakteristik buzlu cam görüntüsü literatür ile uyumludur (Olgu-1). Radyografik olarak fibröz displazinin ayırıcı tanısı; ossifying fibroma, Paget hastalığı, osteomiyelit, anevrizmal kemik kistleri, dev hücreli reperatif granülom ve hiperparatiroidizmde görülen "brown tümörü" ve osteosarkom ile yapılır. Ossifiying fibroma daha ileri yaşlarda genellikle kadınlarda görülür ve radyografide lezyon sınırları nettir. Hiperparatiroidizmde görülen brown tümörü, sıklıkla bilateral olarak görülür ve kemikte ekspansiyona neden olmaz. Paget hastalığı, ileri yaşta ve kafa kemiklerinde yaygın görülür. Ek olarak kanda alkalen fosfataz seviyelerinin yükselmesi gibi biyokimyasal değişikliklere sebep olur. Malign karakterli bir lezyon olan osteosarkom, fibröz displazinin erken evre lezyonları ile karışabilmektedir. Osteosarkomda lezyon sınırları düzensizdir ve periost reaksiyonları (codman üçgeni, güneş ışığı) görülür ${ }^{1,5,6}$. Fibröz displazide tedavi konservatif olmalıdır. Deformite oluşturmayan lezyonlar takip edilebilir. Büyük ve çok sayıda kemiği tutan, deformite oluşturan lezyonlarda ise kısmi rezeksiyonlar yapılabilir ${ }^{14,15}$. Diğer yandan, birkaç fibröz displazi vakasında malign dönüşüm (osteosarkom, fibrosarkom, kondrosarkom) bildirilmiştir ${ }^{16}$. Bu nedenle fibröz displazili olgular uzun dönem takip edilmelidir. Olgumuza etkilenen bölgede kontur düzeltilmesine yönelik cerrahi müdehale planlandı ve hasta uzun dönem takip edilmesi gerektiği konusunda bilgilendirildi (Olgu-1).

Florid osseöz displazi çenelerde nadir görülen benign fibroosseöz bir lezyondur. Genellikle orta yaşlı kadınlarda, mandibular ve maksiller posterior bölgelerde, bilateral ve simetrik olarak görülür ${ }^{17,18}$. Lezyonlar sıklıkla asemptomatiktir, dişli veya dişsiz çenelerde görülebilir ve rutin radyografik değerlendirme sırasında farkedilir ${ }^{19,20}$. Olgumuzda lezyonun mandibula posterior bölgede bilateral, simetrik görülmesi literatür ile uyumludur (Olgu-2). Radyografik görüntü lezyonun gelişim evrelerine bağlıdır. Erken evrede lezyonlar radyolusent, matur evrede etrafı radyolusent hat ile çevrili radyoopak kitleler şeklinde görülür ${ }^{5}$. Ayrıca florid osseöz displazi lezyonları, sadece diş ile ilişkili bölgelerde ve mandibular kanalının süperiorunda lokalizedir $^{20}$. Olgumuzda, KIBT görüntüleri değerlendirildiğinde, lezyonun diş ile ilişkili bölgelerde ve mandibular kanalın üzerinde lokalize olması literatür ile uyumludur (Olgu-2). Radyografik olarak florid osseöz displazinin ayırıcı tanısı; meme ve prostat gibi bazı 
karsinomların çene metastazı, Paget hastalığı, Gardner sendromu ve kronik diffüz sklerozan osteomyelit, fibröz displazi lezyonları ile yapılır. Metastatik çene lezyonları genellikle ağrı, dişlerde mobilite artışı, dudakta parestezi ile ilişkilidir. Ayrıca hastanın tıbbı geçmişi ayrıcı tanıda yardımcı olur ${ }^{1}$. Paget hastalığı, mandibulada yaygın görülür ve kanda alkalin fosfataz seviyelerinin yükselmesi gibi biyokimyasal değişikliklere sebep olur. Gardner sendromu cilt tümörleri ve diş anomalileri ile ilişkilidir. Kronik diffüz sklerozan osteomyelit, mandibulada tek taraflı, ağrı ve şişlikle birlikte görülen inflamatuar bir lezyondur. Mandibulada etkilenen bölgede sınırları belirgin olmayan bir opasite gösterir. Ossifiye fibroma (semento-ossifiye fibroma) bukko-lingual yönde ciddi ekspansiyon yapar. KIBT, konvansiyonel grafilerde benzer sklerotik görünüme sahip lezyonların, florid osseöz displaziden ayırt edilmesinde yararlıdır ${ }^{21}$. Florid osseöz displazi lezyonları asemptomatik ise tedavi gerekli değildir ancak oluşabilecek enfeksiyon için önlem alınmalıdır. Lezyonlar semptomatik ise antibiyotik tedavisi ve sekestrektomi uygulanır ${ }^{22}$. Asemptomatik olan olgumuz için herhangi bir tedavi uygulanmadı, takip önerildi (Olgu2).

Periapikal osseöz displazi genellikle orta yaş grubu kadınlarda ve tipik olarak mandibular anterior diş köklerinde görülen bening fibroosseöz bir lezyondur. Bir veya birden fazla dişi etkileyebilir ve maksiller dişlerde nadiren rastlanır. Radyografik görüntü lezyonun gelişim evrelerine bağlıdır. Erken evrede lezyonlar radyolüsent, mikst evrede radyoopasite artışı görülür, matür evrede ise dar bir radyolusent kenar ile çevrili radyoopak kitleler şeklinde görülür ${ }^{6}$. Radyografik olarak erken evre lezyonlarının ayrıcı tanısı; periapikal kist, granüloma gibi inflamatuar lezyonlar ile yapımalıdır. İleri evre lezyonlarının ayırıcı tanısı ise sementoblastoma ve idiyopatik osteoskleroz (enostoz), kronik sklerozan osteomyelit, ossifiye fibroma ile yapılır. Sementoblastoma, ilgili dişin apikaline yapışıktır, kök rezorpsiyonuna yol açar, klinik olarak semptomatik ve ağrılıdır. İdiyopatik ostesklerozda radyolüsent kapsül yoktur ve lezyon sınırları düzensizdir 6,14

Periapikal osseöz displazide ilgili dişlerin vital olması erken evrede görülen radyolüsent lezyonları, inflamatuar lezyonlardan ayırır. Böylece dişlere uygulanabilecek yanlış tedaviler önlenir. Olgumuz, lezyonun erken evredeki periapikal osseöz displazi ile uyumlu olup ilgili dişlerin vital olması nedeni ile hastaya her- hangi bir tedavi uygulanmadı, takip önerildi (Olgu-3).

Sonuç olarak, kesitsel görüntü veren KIBT ile bening fibroosseöz lezyonların teşhişi kolaylaşmaktadır. Ancak bening fibroosseöz lezyonların radyografide gelişim aşamasına göre farklı göründüğü dikkate alınmalıdır.

K.Tuğçe Temur: ORCID ID: 0000-0001-9947-5679

Erkan Arslan: ORCID ID: 0000-0002-1052-9333

\section{KAYNAKLAR}

1. El-Mofty S. Fibro-Osseous Lesions of the Craniofacial Skeleton: An Update, Head and Neck Pathol 2014;8:432-444.

2. Rajpal K, Agarwal R, Chhabra R, Bhattacharya M. Updated classification schemes for fibroosseous lesions of the oral \& maxillofacial region: A review. IOSR Journal of Dental and Medical Sciences 2014;13:99-103.

3. Chauhan I, Roy S, Garg V, Manchanda K. Fibroosseous lesions of the jaws: An insight, Int J Contemp Dent Med 2014;2014:828-35.

4. McCarthy EF. Fibro-Osseous lesions of the maxillofacial bones. Head Neck Pathol 2013;7:510.

5. Eversole R, Su L, El-Mofty S. Benign fibro-osseous lesions of the craniofacial complex: a review. Head Neck Pathol 2008;2:177-202.

6. White SC, Pharoah MJ. Oral radiology: principles and interpretation. 6th ed. China 2009. 428-53.

7. Kutluay Köklü H, Cankal DA, Bozkaya S, Ergün G, Bar E. Florid cemento-osseous dysplasia: Report of a case documented with clinical, radiographic, biochemical and histological findings. J Clin Exp Dent 2013;5:58-61.

8. Köse $T E$, Köse OD, Karabas HC, Erdem TL, Özcan İ. Findings of florid cemento-osseous dysplasia: a report of three cases. Journal of oral \& maxillofacial res 2013;4:4.

9. MacDonald DS. Maxillofacial fibro-osseous lesions. Clin Radiol 2015;70:25-36.

10. Llyod GA, Lund VJ, Scadding GK. CT of paranasal sinuses and functional endoscopic surgery: a critical analysis of 100 symptomatic patients. J Larinygol Otol 1991;105:181-5. 
11. Livaoğlu M, Bahadır O. Maksiller Sinüste Fibröz Displazi: Olgu Sunumu, Tanı ve Tedavi Yönünden Literatürün İrdelenmesi. F Ü Sağ Bil Tıp Derg 2010; 24:59-61.

12. Törenek K, Yaşa Y, Akgül HM. Monostatik Fibröz Displazi: olgu sunumu. Atatürk Üniv Diş Hek Fak Derg 2015;13:6-9.

13. Ünlü E. Maksiller Fibröz Displazi: Vaka Sunumu. Kocatepe Med J 2014;15:58-61.

14. De Melo WM, Sonoda CK, Hochuli-Vieira E. Monostotic Fibrous Dysplasia of the Mandible. J Craniofac Surg 2012;23:452-4.

15. MacDonald-Jankowski DS. Fibro-osseous lesions of the face and jaws. Clin Radiol 2004;59:11-25.

16. Brademann G, Werner JA, Janig U, Mehdorn HM, Rudert $\mathrm{H}$. Cemento-ossifying fibroma of the petro mastoid region: case report and review of the literature. J Laryngol and Otol 1997; 111:152-5.

17. Sanjai K, Kumarswamy J, Kumar VK, Patil A. Florid cemento osseous dysplasia in association with dentigerous cyst. J Oral Maxillofac Pathol 2010;14:63-8.

18. Beylouni I, Farge P, Mazoyer JF, Coudert JL. Florid cementoosseous dysplasia. Oral Surg Oral Med Oral Pathol Oral Radiol Endod 1998;85:707-711.

19. Kim JH, Song BC, Kim SH, Park YS. Clinical, radiographic, and histological findings of florid cemento-osseous dysplasia: a case report. Imaging Sci Dent 2011;41:139-42.

20. Günhan Ö. Oral ve Maksillofasiyal Patoloji. 1. Baskı. Ankara 2001.159.

21. Yıldırım E, Bağlar S, Ciftçi ME, Ozcan E. Florid cemento-osseous dysplasia: A rare case report evaluated with cone-beam computed tomography. J Oral Maxillofac Pathol 2016;20:329.

22. Sarmento DJ, Monteiro BV, de Medeiros AM, da Silveira EJ. Severe florid cemento-osseous dysplasia: a case report treated conservatively and literature review. Oral Maxillofac Surg 2013;17:436.

\section{Yazışma Adresi}

Uzm. Dt. Katibe Tuğçe Temur e-mail: tugce.uzmez@hotmail.com 